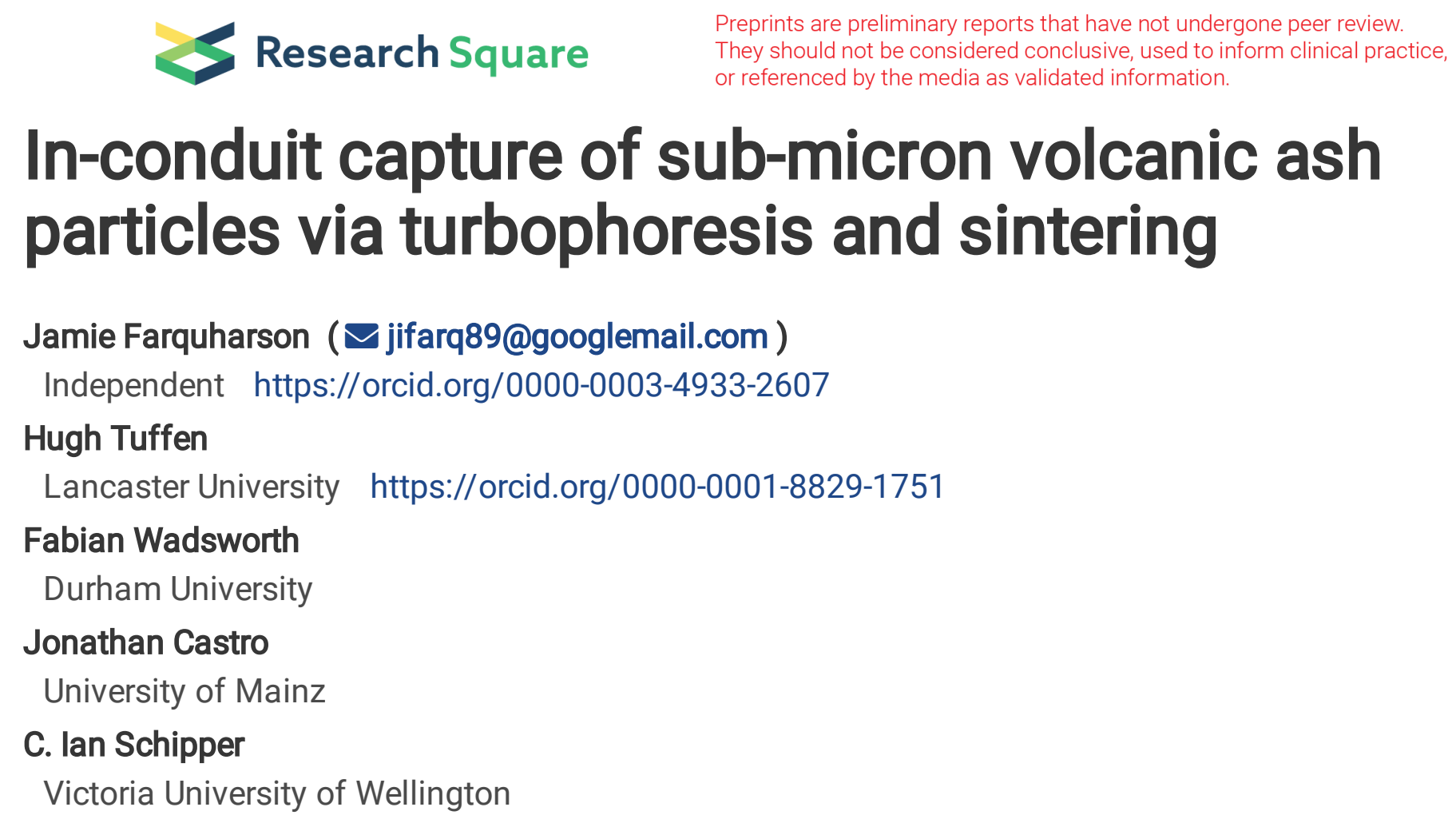

\section{In-conduit capture of sub-micron volcanic ash particles via turbophoresis and sintering}

Jamie Farquharson ( $\nabla_{\text {jifarq89@googlemail.com ) }}$

Independent https://orcid.org/0000-0003-4933-2607

Hugh Tuffen

Lancaster University https://orcid.org/0000-0001-8829-1751

Fabian Wadsworth

Durham University

Jonathan Castro

University of Mainz

C. lan Schipper

Victoria University of Wellington

\title{
Article
}

Keywords:

Posted Date: January 19th, 2022

DOI: https://doi.org/10.21203/rs.3.rs-1152244/v1

License: (c) (1) This work is licensed under a Creative Commons Attribution 4.0 International License.

Read Full License

Version of Record: A version of this preprint was published at Nature Communications on August 11th, 2022. See the published version at https://doi.org/10.1038/s41467-022-32522-7. 


\section{In-conduit capture of sub-micron volcanic ash particles via turbophoresis and sintering}

Jamie I. Farquharson, Hugh Tuffen, Fabian B. Wadsworth, Jonathan M. Castro, C. Ian Schipper

Ash emission in explosive silicic eruptions can have widespread impacts for human health, agriculture, infrastructure, and aviation. Estimates of the total grainsize distribution (TGSD) generated during explosive magma fragmentation underpins eruption models and ash dispersal forecasts. Conventionally, the TGSD constrained via erupted deposits is assumed to match the TGSD produced at explosive fragmentation. Here we present observations from within the vent of a recent rhyolitic eruption (Cordón Caulle, Chile, 2011-2012), demonstrating that fine and ultra-fine ash particles are captured and sintered to fracture surfaces, and thus sequestered in the shallow subsurface, rather than emitted. We establish a conceptual model-uniquely contextualised through a combination of syn-eruptive observations and detailed post-eruption field investigation-in which turbophoresis (particle migration towards zones of lower turbulence) and rapid sintering create an inverse relationship between particle size and the probability of its subsurface capture. Such size-dependent capture efficiency preferentially removes submicron-diameter ash from the erupted componentry, decoupling the erupted size distribution from magmatic source conditions and potentially playing an important role in modulating eruption dynamics.

Understanding the controls on silicic volcanic eruption style is a grand challenge in geoscience ${ }^{1}$. Silicic eruptions-and rhyolitic eruptions in particular-remain enigmatic, in part because very few such eruptions have been observed. While key observations of the preserved and variably eroded deposits of past eruptions have proved invaluable in our understanding of silicic eruptive dynamics ${ }^{2-5}$, recent eruptions at Chaitén (2008-2009) and Cordón Caulle (2011-2012), both in Chile, were witnessed directly and have allowed us to observe how rhyolitic eruptive processes proceed in real-time ${ }^{6-9}$. The blurred transition between explosive eruptions and subsequent lava effusion, together with evidence for shallow in-conduit reassembly and welding of pyroclastic debris, has led to a model in which effusive lava may be produced top-down from the products of the explosive phase ${ }^{2,10}$. This is consistent with the presence of sintering textures in all phases of a silicic eruption: obsidian pyroclasts and welded pumice in fall deposits ${ }^{11-13}$, tuffisites in volcanic bombs ${ }^{10,14,15}$, and partially sintered surfaces in the effusing lava itself ${ }^{2}$. This model raises questions about the poorly constrained structure of the uppermost conduit feeding the eruption as well as the relationship between emitted products and the atdepth source parameters.

The total grainsize distribution (TGSD) of erupted volcanic ash particles controls their subsequent transport and sedimentation ${ }^{16,17}$, related respiratory health hazards ${ }^{18}$, their preservation as geochronologically important tephra layers ${ }^{19}$, their geochemical reactivity ${ }^{20}$, and their use as indicators of the magnitudes of past volcanic events ${ }^{21,22}$. A key question remains: how does the TGSD of particles generated via subsurface 
fragmentation relate to the size distribution of particles emitted into the atmosphere and fed into plumes? Dispersal models assume an inverse relationship between particle size and mobility, with the smallest ash fraction found most distal to the vent due to its low settling velocity ${ }^{23}$, and larger clasts being constrained closer to the vent ${ }^{24}$. However, recent field observations demonstrate the existence of $0.1-100 \mu \mathrm{m}$ variably sintered ash particles coating the fractures that provided pathways for ash emission ${ }^{2}$. The demonstrable capture of fine ash within the vent itself shows that a re-evaluation of microscale ash emission processes is necessary.

\section{Results: In-vent observations from the 2011-2012 Cordón Caulle eruption}

The 2011-2013 Cordón Caulle eruption was initially characterised by a Plinian phase during which the ash plume reached $>15 \mathrm{~km}$ height (Fig. 1a); this soon gave way to a tenmonth-long hybrid explosive-effusive phase characterised by intermittent ash plumes, with synchronous lava effusion and explosive activity from a common vent ${ }^{25}$. Syneruption videography in January 2012 revealed near-continuous ash venting with sporadic Vulcanian blasts occurring from two highly-fractured $\sim 50-80 \mathrm{~m}$-diameter lava piles within a single coalesced, horseshoe-shaped tephra cone9. Ash plumes, 2-5 km high, emanated from clusters of sub-vents ranging from near-point sources to arcuate, 10-30 m-long fractures (Fig. 1b-d). Sub-vents exhibited variable transitions between quiescence, steam venting, dilute ash venting, and incandescent bomb emission over timescales of 1-10 seconds, with apparent correlations between separate sub-vent activity indicating their subsurface connectivity. Bombs exited the vent at $\sim 100 \mathrm{~m} . \mathrm{s}^{-1}$, and largely fell within the tephra cone or on raised ground to the north and north east.

Field investigation in January 2014, shortly following cessation of eruptive activity, allowed the correlation of the syn-eruptive observations of ash venting processes directly with specific structures within the vent (Figs 1e-g). In particular, here we describe veneered surfaces of in-situ fracture planes (Fig. 1f,g), which are the surface expression of ash venting pathways active during the prolonged hybrid phase of the eruption. By January 2014, the vent areas consisted of fractured obsidian lava with ubiquitous red fracture surfaces (Fig. 1f,g). These-as with tuffisite structures found in the distal flowfield ${ }^{15}$-correspond to sub-vent structures observed in 2012 (Fig. 1b-d) ${ }^{9}$. They range from smooth, curviplanar surfaces extending over several meters to complex smallerscale surfaces that follow pre-existing lava carapace cooling joints or wend between brecciated lava clasts (Fig. 1f). In-situ fracture surfaces display prominent, predominantly vertical grooves and impact marks (Fig. 1f), but negligible evidence for shear displacement. Surfaces are coated by variably sintered, fine-grained ash veneers, ranging from dense, red indurated layers to dusty pink/yellow coatings that thicken into surface hollows and appear to be vertically extensive into the lava. Veneers are several microns to millimetres thick (Figs 1f,g) and contain embedded, angular larger crystalline lava clasts $\leq 10 \mathrm{~cm}$ across, themselves coated by a veneer of glassy ash.

Scanning electron microscopy of ash veneers reveals vesicle-free, glassy ash shards and rounded fragments with grain diameters in the range 0.1-100 $\mu \mathrm{m}$ (Fig. 2a-c) and predominantly $<1 \mu \mathrm{m}$ (Fig 2d). Ash morphologies range from angular, with conchoidal 
fracture surfaces, to near-spherical and droplet-like with narrow necks between ash particles and other surfaces (Fig. 2c). In some cases, the ash particles are coalesced into smooth surface coatings (Figs 1f \& 2a). Clusters of strongly-sintered clasts $\sim 10 \mu \mathrm{m}$ across and aligned, millimetric pellet-like agglomerations that themselves consist of finer-grained ash. Pellets are aligned parallel to the ropy texture conspicuous on many surfaces (Fig. 1f). A thin outer layer of coarser clasts commonly adheres to hollows in the strongly-sintered ash veneer, whereas some veneer-free surfaces instead display scouring. We interpret these textures as representing varying degrees of sintering ${ }^{26,27}$, which is most progressed in the finest-grained coating material where there is nearcomplete inter-particle porosity destruction ${ }^{27}$ and where smooth surface coatings result (Fig. 2). Larger particles, pellets, and aggregates are less well sintered with incipient necks representing only the early stages of sintering 27 . We infer the scouring to represent a combination of mechanical abrasion and corrosion of glass.

\section{Capture and sticking of volcanic droplets}

The observation of variably sintered fine-ash veneers coating the margins of what were active ash-venting pathways can be described in the context of our current understanding of silicic explosive-effusive transitions ${ }^{2,10}$. Here, we distil three starting observations that can be used to underpin a description of the dynamics that form the observed ashveneers, and help us to interpret their significance for eruptions. First, ash must have been generated down to the ultra-fine, sub-micron particle sizes observed in the sintered veneers (Fig 2). Second, the particles must have been transported in a gas-ash dispersion (observed in ash-laden jets during the eruption and feeding the intermittent gas-ash plumes that characterise the hybrid explosive-effusive eruptive style; Fig. 1b). Third, the fine particles must have sintered rapidly to the fracture walls without rebounding or being re-entrained into the bypassing flow. From these observations, we posit that the grainsize of the material in the sintered surface deposits-extremely fine when compared with fall deposits derived from the same eruptive phases 28,29 - governed their preferential capture and sintering to the surface. This in turn requires an exceptional flow and depositional environment that would have fostered fines being preferentially transported to the walls and sequestered in the boundary layer flow at the wall, despite there being proximal and simultaneous high-energy flows capable of transporting larger particles beyond the walls and into the erupting plume. We use these conceptual starting points to underpin a scaling analysis of the transport and deposition regimes involved in order to gain insight in to the timescales and mechanisms involved.

The first question is whether or not particles in turbulent flow (see Methods) will contact the wall, or be transported through the fracture without interacting with the wall. The characteristic timescale of motion of a particle of diameter $d$ in a flow is $\lambda_{p}=\rho d^{2} /\left(18 \mu_{f}\right)$, where $\rho$ is the particle density and $\mu_{f}$ the dynamic viscosity of the carrier phase. The response of the particle to flow turbulence is described by the Stokes number St, which is the ratio of $\lambda_{p}$ to a characteristic fluid timescale $\lambda_{f}$, in turn a function of a given eddy size and velocity within the flow. Therefore, St $=\rho d^{2} /\left(18 \mu_{f} \lambda_{f}\right)$ where St $\gg 1$ represents particles that are not well-coupled to the flow and may impact the walls. The Stokes 
number also correlates with the organisation of particles within an eddy, controlling their local concentration or dispersal as a function of their size $3^{30}$.

We can place bounds on the maximum and minimum eddy sizes possible in turbulent flow as corresponding to either the fracture aperture $L$ (upper bound) or the Kolmogorov lengthscale $\delta_{K}$ (lower bound), respectively. First, the upper bound on the maximum eddy size is associated with a maximum fluid timescale $\lambda_{f}=\lambda_{O}=L /\langle u\rangle$, where $\langle u\rangle$ is the mean velocity of the flow. Second, the minimum eddy size is associated with the Kolmogorov timescale $\lambda_{f}=\lambda_{K}=\sqrt{v / \varepsilon}$, where $v$ is the kinematic viscosity of the fluid, $\varepsilon=v^{3} / \delta_{K}^{4}$ is the average rate of dissipation of turbulence kinetic energy per unit mass, and $\delta_{K}=v /\langle u\rangle$. At high Reynolds number (Methods), turbulence generates eddies from the scale of $\delta_{K}$ to $L$, meaning that there exists a range of potential St associated with any given particle size, depending on the eddy size local to the particle. In $u-R$ space (Fig 3a), we can delineate three regimes of particle response to turbulent flow: St $\gg 1$, wherein particles cross streamlines and may impact walls; St $\ll 1$, wherein particles follow streamlines; and St $\sim 1$, wherein particles will tend to concentrate (cluster) at the periphery of eddies, potentially decoupling from the gyratory flowpath ${ }^{11}$ (Fig 3a). In detail, the condition St $=1$ may be met depending on the eddy size (between $\delta_{K}$ and $L$ ). In Fig $3 \mathbf{a}$ we plot these regimes for the fracture width $L=0.01 \mathrm{~m}$ measured in the vent at Cordón Caulle; notably, the $S t \sim 1$ regime corresponds well with the observed particle size distribution at velocities of the order of $\langle u\rangle$. Experiments and simulations illustrate that when St $\sim 1$, non-uniform particle distribution is observed ${ }^{30,31}$. The fact that the observed grainsize distribution falls within the range whereby St 1 suggests that this size fraction in particular is dynamically decoupled from the carrier phase and will cluster in the flow. Particles that are not large enough to be on truly ballistic trajectories (St 》 1) and not small enough to follow the smallest eddy flows in an effectively passive manner (St $\ll 1$ ) exhibit a particular tendency to migrate from regions of high turbulence to low-turbulence-intensity regions ${ }^{22,33}$ via a phenomenon termed turbophoresis.

Turbophoresis serves to segregate particles axially toward the wall region, and is facilitated by a viscous boundary layer at the wall that in turn arises from the velocity differential beyween $\langle u\rangle$ and $u_{T}$ (the boundary friction velocity34; see Methods). Having determined that a portion of the particles are at St $>1$ and can undergo a particle-wall interaction, we now determine the dynamics of that interaction by considering the particles-at magmatic temperatures-to effectively be viscous droplets. At the droplet scale, isothermal dynamics can be characterised by the Eötvös, Ohnesorge, and Weber numbers (Eo, Oh, and We, respectively, see Methods).

Taking a representative value of surface tension $\Gamma=0.36 \mathrm{~N} \mathrm{~m}^{-1}$ for degassed volcanic particles35-37, characteristic particle radii $R$ of order $1.3 \times 10^{-7} \leq R \leq 2.6 \times 10^{-6} \mathrm{~m}$ (Fig. 2d) yield Eo $\ll 1$, indicating that the effect of body forces arising from gravity are negligible. In addition, $\mathrm{Oh} \gg \sqrt{\mathrm{We}}$ for temperate-dependent droplet viscosity $\mu(T)$ of 1.56 $\times 10^{8} \mathrm{~Pa} \mathrm{~s}$ [refs. ${ }^{88,39}$, where $T=900{ }^{\circ} \mathrm{C}$. Taking $\langle u\rangle=100 \mathrm{~m} \mathrm{~s}^{-1}$ to be the characteristic exit velocity of particles based on image velocimetry 9 and $u_{\theta}$ to be the impact angle-scaled velocity (Methods), We is typically $>1$. In Fig. 3b we plot upper and lower bounds on the Oh-We plane ${ }^{40}$. The majority of feasible values plot in regime IV, in which the force 
driving the impact droplet-wall interaction is the impact force itself, capillary forces at the contact line of the droplet are negligible, and the force resisting the impact interaction arises from the viscosity of the droplet. Consequently, we can establish the characteristic timescale of the droplet-wall interaction as $\lambda_{d}=\mu\left(\rho u_{\theta}^{2}\right)^{-1}$, where $\rho$ is droplet density.

Finally, we address whether or not a particle can sinter on the timescale available in the interaction. To assess this, we appeal to the observation that in all droplet-wall interactions reproduced experimentally, interaction will result in sticking if the droplet is viscous at the time of impact 40,41 . As more droplets interact and stick, the sintering process that creates a less porous and stronger deposit layer (i.e. the "porosity destruction" inferred above) is governed by the timescale for particle viscous sintering-driven by surface tension at the interface of the particles-and is $\lambda_{\Gamma}=R \mu / \Gamma$, yielding timescales $\sim 55^{-1104} \mathrm{~s}$. These values are similar to the interaction times $7 \leq \lambda_{d} \leq 647 \mathrm{~s}$ for $100 \geq u_{\theta} \geq 10 \mathrm{~m} \mathrm{~s}^{-1}$, and are also generally within the timescale of ash-jetting episodes (seconds to tens of seconds 9 ). We note that any nonzero pressure differential acting on the droplets in excess of the gas pressure will serve to accelerate the sintering process $^{2,26,27}$. Recent work has shown that small rhyolitic ash particles $\left(R \sim 10^{-6} \mathrm{~m}\right.$ and smaller) will sinter more readily than larger particles, despite a smaller size fraction being more thoroughly degassed at the Earth's surface and therefore having a higher viscosity ${ }^{2}$.

Particle organisation and entrapment could be enhanced by electrostatic forces42,43, particle-dispersion heating by any particle-particle and particle-wall friction at high particle volume fractions, the growth of viscous boundary layers during waning flow, and large wall asperities that host low velocity eddies. Taken together, this analysis demonstrates (1) the turbulent motion of the carrier phase should migrate fines towards the fracture/conduit walls, in particular (2) those particles within the $10^{-7} \leq R \leq 10^{-5} \mathrm{~m}$ range are most likely to decouple from the carrier phase and subsequently impact the walls and interact, and (3) that interacting particles can stick and sinter. Critically, our analysis highlights that the small grainsize is the key parameter at each step of preferential segregation, transport, and sticking.

\section{Grain size fractionation}

In this work, we show that fine volcanic ash particles have stuck to fracture planes during ash venting, and were therefore captured and sintered while capable of viscous deformation. It is small particles at the low end of the high-Stokes-number regime that will be preferentially transported by turbophoresis and therefore sintered to the walls; as such, fine particles are fractionated from the TGSD prior to eruption into the plume. TGSD is used as a window into pre- and syn-eruptive fragmentation 44, and to directly infer sub-surface magmatic processes ${ }^{28}$. Conventionally, reconstructed TGSDs informalbeit indirectly-the mechanisms, efficiency, and depth of magma fragmentation and the total explosive energy release $45-47$. Moreover, TGSDs are used to determine initial tephra size distributions, a critical source term for ash dispersal models ${ }^{28,48}$. Fundamentally, such estimates rely on the basic assumption that reconstructed TGSDs are directly related to these source parameters; however, secondary processes may modify the size 
distribution of primary fragmentation products ${ }^{13}$. The TGSD from the Córdon Caulle 2011 eruption has been reconstructed or otherwise estimated by various methods ${ }^{16,28,29}$. These estimates differ, both in terms of range and modality (Fig. 4a); importantly however, there is little overlap with the size distribution associated with the features of this study. The fine ash fraction observed here therefore reflects more energetic fragmentation 45 than the relatively larger fraction captured by post-emplacement approximations (Fig. 4c), which cannot fully capture the energetics or mechanics of fragmentation at depth both due to fine-ash entrapment within the conduit, and to syn- and post-eruption processes including aggregation, winnowing, and remobilisation 49.

The capture and sintering of particles in the volcanic sub-surface has recently been suggested as a mechanism to assemble silicic lava bodies ${ }^{2,10}$ as a whole. A tantalising implication of this model is that the process of within-conduit sticking and sintering is volumetrically significant relative to the whole erupted volume, and may mean that the fines production at depth (1) is volumetrically substantial, and (2) represents a significant proportion of the explosive energy 45 . The downstream implication is that the fragmentation energy may be higher than can be predicted by observations of grain sizes in fall deposits-reinforced by recent recognition that many silicic pumice clasts are in fact sintered agglomerates ${ }^{13}$. Other processes-including shear or abrasion mechanisms $5^{50,5^{1}}$ and related in-conduit comminution processes ${ }^{2}-$ act to divorce grain size distributions from the magmatic source conditions, increasing the fines proportion relative to the size distribution produced at true magmatic fragmentation at depth. By contrast, the process we invoke to explain our observations acts in the opposite direction, sequestering fine grains and leaving a relatively coarser grain size distribution to erupt in the plume than that produced at magmatic fragmentation (Fig. 4c). In concert, these effects both may strongly decouple the erupted pyroclast and ash size distribution from the magmatic source conditions.

\section{Implications for silicic eruption dynamics}

The Cordón Caulle eruption allowed the observation of contemporaneous explosive and effusive behaviour, a phenomenon which has since been interpreted as a product of continued in-conduit explosive fragmentation 15 and variable reaggregation of clasts via sintering ${ }^{2}$. Our data further support this hypothesis. The measured size distribution is indicative of highly efficient fragmentation 46,53 and means that these ashy veneers record fragmentation processes at Cordón Caulle that are not captured through existing TGSD reconstructions (Fig. 4a). It is likely that energetic magmatic fragmentation was sustained throughout the hybrid phases of the Cordón Caulle eruption ${ }^{2}$, with in-conduit organisation and sintering effectively removing the evidence of this process from the erupted componentry. This is supported by evidence of ash-coated fracture planes distal to the main vent (Fig. 5a). In order to fully capture the dynamics of hybrid silicic volcanism-critical to hazard mitigation-models of eruptive activity must couple the influence of continuous, energetic fragmentation and the preferential in-conduit entrapment of ultrafine ash.

There is mounting evidence that silicic eruptions are characterised by explosive fragmentation and variable in-conduit re-aggregation of magma ${ }^{2,3,11,13}$; the fact that the 
vent "nozzles" examined here preserve evidence of essentially the same processes suggests that these mechanisms may be self-similar across spatial scales. We show that particle capture and sticking are functions of conduit or fracture width, which may itself evolve as the walls are progressively coated with a sequestered ash fraction. A key implication of this model is that the transport of ash from its fragmentation source to the vent not only modifies the subsequent recorded componentry, but may in fact directly influence eruptive dynamics by altering variables such as conduit width, particle density, and bulk viscosity. In addition, our model predicts that gradual waning of vent flux (i.e. a decrease in $\langle u\rangle$ : Fig. 3a) may facilitate the capture of a progressively larger size fractionas observed elsewhere in the flowfield (Fig. 4a) -potentially to the point of occluding the fracture entirely. We have focussed here on ash-coated nozzle structures at the main vent of Cordón Caulle; we note, however, that not only do comparable features exist throughout the flowfield (Fig. 4a), but also at other rhyolitic volcanoes: Figure $4 \mathbf{b}$ shows evidence exists of similarly veneered fracture surfaces at Medicine Lake volcano (USA). This fact suggests that the processes described are ubiquitous throughout rhyolitic systems and occur throughout hybrid activity-even in the earliest stages . Considering post-fragmentation processes in terms of a hot, particle-laden (i.e. dusty) gas flow thus represents a frontier in silicic eruption modelling. 


\section{References}

1. Cassidy, M., Manga, M., Cashman, K. \& Bachmann, O. Controls on explosive-effusive volcanic eruption styles. Nat Commun 9, 2839 (2018).

2. Wadsworth, F. B., Llewellin, E. W., Vasseur, J., Gardner, J. E. \& Tuffen, H. Explosiveeffusive volcanic eruption transitions caused by sintering. Sci. Adv. 6, eaba7940 (2020).

3. Black, B. A., Manga, M. \& Andrews, B. Ash production and dispersal from sustained lowintensity Mono-Inyo eruptions. Bull Volcanol 78, 57 (2016).

4. Berlo, K. et al. Element variations in rhyolitic magma resulting from gas transport. Geochimica et Cosmochimica Acta 121, 436-451 (2013).

5. Cabrera, A., Weinberg, R. F., Wright, H. M. N., Zlotnik, S. \& Cas, R. A. F. Melt fracturing and healing: A mechanism for degassing and origin of silicic obsidian. Geology 39, 67-70 (2011).

6. Tuffen, H., James, M. R., Castro, J. M. \& Schipper, C. I. Exceptional mobility of an advancing rhyolitic obsidian flow at Cordón Caulle volcano in Chile. Nature Communications 4, 2709 (2013).

7. Farquharson, J. I., James, M. R. \& Tuffen, H. Examining rhyolite lava flow dynamics through photo-based 3D reconstructions of the 2011-2012 lava flowfield at Cordón-Caulle, Chile. Journal of Volcanology and Geothermal Research 304, 336-348 (2015).

8. Castro, J. M. \& Dingwell, D. B. Rapid ascent of rhyolitic magma at Chaitén volcano, Chile. Nature 461, 780-783 (2009).

9. Schipper, C. I., Castro, J. M., Tuffen, H., James, M. R. \& How, P. Shallow vent architecture during hybrid explosive-effusive activity at Cordón Caulle (Chile, 2011-12): Evidence from 
direct observations and pyroclast textures. Journal of Volcanology and Geothermal Research 262, 25-37 (2013).

10. Schipper, C. I. et al. Silicic conduits as supersized tuffisites: Clastogenic influences on shifting eruption styles at Cordón Caulle volcano (Chile). Bull Volcanol 83, 11 (2021).

11. Gardner, J. E., Llewellin, E. W., Watkins, J. M. \& Befus, K. S. Formation of obsidian pyroclasts by sintering of ash particles in the volcanic conduit. Earth and Planetary Science Letters 459, 262-263 (2017).

12. Watkins, J. M., Gardner, J. E. \& Befus, K. S. Nonequilibrium degassing, regassing, and vapor fluxing in magmatic feeder systems. Geology 45, 183-187 (2017).

13. Giachetti, T. et al. The products of primary magma fragmentation finally revealed by pumice agglomerates. Geology (2021) doi:10.1130/G48902.1.

14. Castro, J. M. et al. The role of melt-fracture degassing in defusing explosive rhyolite eruptions at volcán Chaitén. Earth and Planetary Science Letters 333-334, 63-69 (2012).

15. Castro, J. M., Bindeman, I. N., Tuffen, H. \& Ian Schipper, C. Explosive origin of silicic lava: Textural and $\delta \mathrm{D}-\mathrm{H} 2 \mathrm{O}$ evidence for pyroclastic degassing during rhyolite effusion. Earth and Planetary Science Letters 405, 52-61 (2014).

16. Bonadonna, C., Cioni, R., Pistolesi, M., Elissondo, M. \& Baumann, V. Sedimentation of long-lasting wind-affected volcanic plumes: the example of the 2011 rhyolitic Cordón Caulle eruption, Chile. Bull Volcanol 77, 13 (2015).

17. Beckett, F. M. et al. Sensitivity of dispersion model forecasts of volcanic ash clouds to the physical characteristics of the particles. Journal of Geophysical Research: Atmospheres 120, 11,636-11,652 (2015). 
18. Horwell, C. J. \& Baxter, P. J. The respiratory health hazards of volcanic ash: a review for volcanic risk mitigation. Bull Volcanol 69, 1-24 (2006).

19. Lowe, D. J. Tephrochronology and its application: A review. Quaternary Geochronology 6, $107-153$ (2011).

20. Delmelle, P., Villiéras, F. \& Pelletier, M. Surface area, porosity and water adsorption properties of fine volcanic ash particles. Bull Volcanol 67, 160-169 (2005).

21. Alfano, F. et al. Reconstruction of total grain size distribution of the climactic phase of a long-lasting eruption: the example of the 2008-2013 Chaitén eruption. Bull Volcanol 78, 46 (2016).

22. Spanu, A., Michieli Vitturi, M. de' \& Barsotti, S. Reconstructing eruptive source parameters from tephra deposit: a numerical study of medium-sized explosive eruptions at Etna volcano. Bull Volcanol 78, 59 (2016).

23. Pioli, L., Bonadonna, C. \& Pistolesi, M. Reliability of Total Grain-Size Distribution of Tephra Deposits. Sci Rep 9, 10006 (2019).

24. Mastin, L. G. et al. A multidisciplinary effort to assign realistic source parameters to models of volcanic ash-cloud transport and dispersion during eruptions. Journal of Volcanology and Geothermal Research 186, 10-21 (2009).

25. Silva Parejas, C., Lara, L. E., Bertin, D., Amigo, A. \& Orozco, G. The 2011-2012 eruption of Cordón Caulle volcano (Southern Andes): Evolution, crisis management and current hazards. $9382(2012)$.

26. Wadsworth, F. B. et al. Sintering of viscous droplets under surface tension. Proc. R. Soc. A. 472, 20150780 (2016). 
27. Wadsworth, F. B. et al. A general model for welding of ash particles in volcanic systems validated using in situ X-ray tomography. Earth and Planetary Science Letters 525, 115726 (2019).

28. Costa, A., Pioli, L. \& Bonadonna, C. Assessing tephra total grain-size distribution: Insights from field data analysis. Earth and Planetary Science Letters 443, 90-107 (2016).

29. Reckziegel, F., Folch, A. \& Viramonte, J. ATLAS-1.0: Atmospheric Lagrangian dispersion model for tephra transport and deposition. Computers \& Geosciences 131, 41-51 (2019).

30. Burgisser, A., Bergantz, G. W. \& Breidenthal, R. E. Addressing complexity in laboratory experiments: the scaling of dilute multiphase flows in magmatic systems. Journal of Volcanology and Geothermal Research 141, 245-265 (2005).

31. Hogan, R. C. \& Cuzzi, J. N. Stokes and Reynolds number dependence of preferential particle concentration in simulated three-dimensional turbulence. Physics of Fluids 13, 2938 (2001).

32. Caporaloni, M., Tampieri, F., Trombetti, F. \& Vittori, O. Transfer of Particles in Nonisotropic Air Turbulence. Journal of the Atmospheric Sciences 32, 565-568 (1975).

33. Reeks, M. W. The transport of discrete particles in inhomogeneous turbulence. Journal of Aerosol Science 14, 729-739 (1983).

34. Schlichting, H. \& Gersten, K. Boundary-Layer Theory. (Springer, 2016).

35. Lange, R. A. A revised model for the density and thermal expansivity of $\mathrm{K} 2 \mathrm{O}-\mathrm{Na} 2 \mathrm{O}-\mathrm{CaO}-$ MgO-Al 2 O 3 -SiO 2 liquids from 700 to $1900 \mathrm{~K}$ : extension to crustal magmatic temperatures. Contributions to Mineralogy and Petrology 130, 1-11 (1997).

36. Heiken, G. Atlas of Volcanic Ash. (1974).

37. Walker, D. \& Mullins, O. and Implications for Melt Structure. 8. 
38. Castro, J. M. et al. Storage and eruption of near-liquidus rhyolite magma at Cordón Caulle, Chile. Bull Volcanol 75, 702 (2013).

39. Giordano, D., Russell, J. K. \& Dingwell, D. B. Viscosity of magmatic liquids: A model. Earth and Planetary Science Letters 271, 123-134 (2008).

40. Schiaffino, S. \& Sonin, A. A. Molten droplet deposition and solidification at low Weber numbers. Physics of Fluids 9, 3172-3187 (1997).

41. Giehl, C., Brooker, R. A., Marxer, H. \& Nowak, M. An experimental simulation of volcanic ash deposition in gas turbines and implications for jet engine safety. Chemical Geology 461, $160-170$ (2017).

42. Sparks, R. S. J. et al. Volcanic Plumes. (Wiley, 1997).

43. Gilbert, J. S., Lane, S. J., Sparks, R. S. J. \& Koyaguchi, T. Charge measurements on particle fallout from a volcanic plume. Nature 349, 598-600 (1991).

44. Jones, T. J. \& Russell, J. K. Ash production by attrition in volcanic conduits and plumes. Sci $\operatorname{Rep} 7,5538$ (2017).

45. Zimanowski, B., Wohletz, K., Dellino, P. \& Büttner, R. The volcanic ash problem. Journal of Volcanology and Geothermal Research 122, 1-5 (2003).

46. Kueppers, U., Scheu, B., Spieler, O. \& Dingwell, D. B. Fragmentation efficiency of explosive volcanic eruptions: A study of experimentally generated pyroclasts. Journal of Volcanology and Geothermal Research 153, 125-135 (2006).

47. Perugini, D. \& Kueppers, U. Fractal analysis of experimentally generated pyroclasts: A tool for volcanic hazard assessment. Acta Geophys. 60, 682-698 (2012). 
48. Eychenne, J., Cashman, K., Rust, A. \& Durant, A. Impact of the lateral blast on the spatial pattern and grain size characteristics of the 18 May 1980 Mount St. Helens fallout deposit. Journal of Geophysical Research: Solid Earth 120, 6018-6038 (2015).

49. Dominguez, L. et al. Aeolian Remobilisation of the 2011-Cordón Caulle Tephra-Fallout Deposit: Example of an Important Process in the Life Cycle of Volcanic Ash. Front. Earth Sci. 7, (2020).

50. Cagnoli, B. \& Manga, M. Granular mass flows and Coulomb's friction in shear cell experiments: Implications for geophysical flows. Journal of Geophysical Research: Earth Surface 109, (2004).

51. Mueller, S. B., Lane, S. J. \& Kueppers, U. Lab-scale ash production by abrasion and collision experiments of porous volcanic samples. Journal of Volcanology and Geothermal Research 302, 163-172 (2015).

52. Dufek, J., Manga, M. \& Patel, A. Granular disruption during explosive volcanic eruptions. Nature Geosci 5, 561-564 (2012).

53. Fowler, A. C. \& Scheu, B. A theoretical explanation of grain size distributions in explosive rock fragmentation. Proc. R. Soc. A. 472, 20150843 (2016).

54. Stasiuk, M. V. et al. Degassing during magma ascent in the Mule Creek vent (USA). Bull Volcanol 58, 117-130 (1996).

55. Kolzenburg, S. et al. Strength and permeability recovery of tuffisite-bearing andesite. Solid Earth 3, 191-198 (2012). 


\section{Methods}

\section{Plume height}

Measurements of plume height were collected by El Servicio Nacional de Geología y Minería (SERNAGEOMIN) and Observatorio Volcanológico de los Andes del Sur (OVDAS) 25 .

\section{Videography}

Activity was recorded in January 2012 using a Canon XF105 video camera at 25 FPS in visible light mode. For further details, the reader is referred to ref. 9.

\section{Microscopy and grainsize analysis}

Scanning Electron Microscope (SEM) images were collected at the University of Liverpool, with a Philips XL30 tungsten filament SEM used on carbon-coated standard petrographic thin sections. The grain sizes discussed here are generally too small for many conventional analyses. In order to determine a grain size distribution, the grain diameters from a representative SEM image were manually measured with ImageJ, and diameters converted to a mass distribution by assuming a spherical particle geometry, with melt density as defined previously.

\section{Dimensionless number calculation}

Flow turbulence in a wall-bounded particle-laden gas flow is characterised by the Reynolds number $\operatorname{Re}=\langle u\rangle L / v$, where $\langle u\rangle$ is the mean velocity of the flow, $L$ a characteristic lengthscale (in this case the fracture width), and $v$ the kinematic viscosity of the fluid. In flow through a slot geometry, fully developed turbulence is expected when $\mathrm{Re} \geq 2900$ [ref.34]. Given estimates of $\langle u\rangle \sim 100 \mathrm{~m} . \mathrm{s}^{-1}$ [ref. 9], $0.01<L<1 \mathrm{~m}$ [refs. $4,9,54,55]$, and $v(T)=1.4 \times 10^{-4} \mathrm{~m}^{2} \mathrm{~s}^{-1}$, gas venting through fractures during the CordónCaulle eruption can be assumed to be highly turbulent $\left(7.14 \times 10^{3} \lesssim \operatorname{Re} \lesssim 7.14 \times 10^{5}\right)$.

At the droplet scale, isothermal dynamics can be characterised by the Eötvös (Eo), Ohnesorge (Oh), and Weber (We) numbers. Eo defines the ratio of gravitational and surface tension forces: Eo $=\rho g R^{2} / \Gamma$, where $\rho$ is droplet density, $g$ is gravitational acceleration, $R$ is the particle radius $(d / 2)$, and $\Gamma$ is interfacial tension at the wall. Oh characterises the relative importance of viscous and inertial forces arising from capillary flow: $\mathrm{Oh}=\mu / \sqrt{\rho \Gamma R}$, where $\mu$ is droplet viscosity. Weber number We scales the effects of inertia and surface tension forces: $\mathrm{We}=\rho R u_{\theta}^{2} / \Gamma$, where $u_{\theta}$ is the relative droplet velocity, here scaled by the impact angle $\theta$ such that $u_{\theta}=\cos \theta\langle u\rangle$. Note that for a uniform distribution of potential impact angles $0<\theta<\pi, 50 \%$ of $u_{\theta}$ will be $87 \mathrm{~m} \mathrm{~s}^{-1}$ or greater: only at very high 'glancing' impact angles does $u_{\theta}$ approach zero. We $\gg 1$ and We $\ll 1$ denote the inertial and capillary fields respectively; for $\mathrm{Oh}$, the critical value is given by 
$\sqrt{\mathrm{We}}$ such that $\mathrm{Oh} \gg \sqrt{\mathrm{We}}$ and $\mathrm{Oh} \ll \sqrt{\mathrm{We}}$ denote the viscous and inertial fields, respectively 40 .

\section{Boundary layer thickness calculation}

In the region of fluid adjacent to the wall, there is a sub-layer in which the velocity of the bypassing fluid drops to lower values compared with the centre-line velocity. In order to assess the extent to which this sub-layer is laminar and represents a viscous boundary layer of appreciable thickness, we scale the dimensionless normal distance from the wall as $\bar{y}=y u_{T} / v$, where $y$ is the dimensional wall-normal direction, and $u_{T}$ is the boundary friction velocity34. To a first-order approximation, the viscous sub-layer occurs at $\bar{y}<10$, a region in which the velocity profile is approximately linear $u(y)=\bar{y} u_{T}$ (ref: 34). This scaling implicates $u_{T}$ as the key unknown, and while the standard scaling is $u_{T}=\sqrt{\tau_{w} / \rho_{f}}$, where $\rho_{f}$ is the fluid density, this still leaves $\tau_{w}$ as an unknown 34 . Instead, we use the approximation $u_{T} \approx 0.05\langle u\rangle$ for fully developed turbulence, which implies that the thickness of the region at $\bar{y}<10$ is at $y_{v}=200 v /\langle u\rangle$. Given the bounds on $\langle u\rangle$ and $v$ used earlier, this results in a minimum viscous boundary layer of thickness $y_{v} \approx 2.8 \times 10^{-4} \mathrm{~m}$. This is larger than both the surface roughness lengthscale, and the particle sizes observed at the surface (Fig. 2b), implying that the flow in this region will be hydraulically smooth. We note that this simple scaling implies that $y_{v} \propto\langle u\rangle^{-1}$, for which waning flow velocities would result in thicker boundary layers and more opportunity for particle entrainment and capture. 

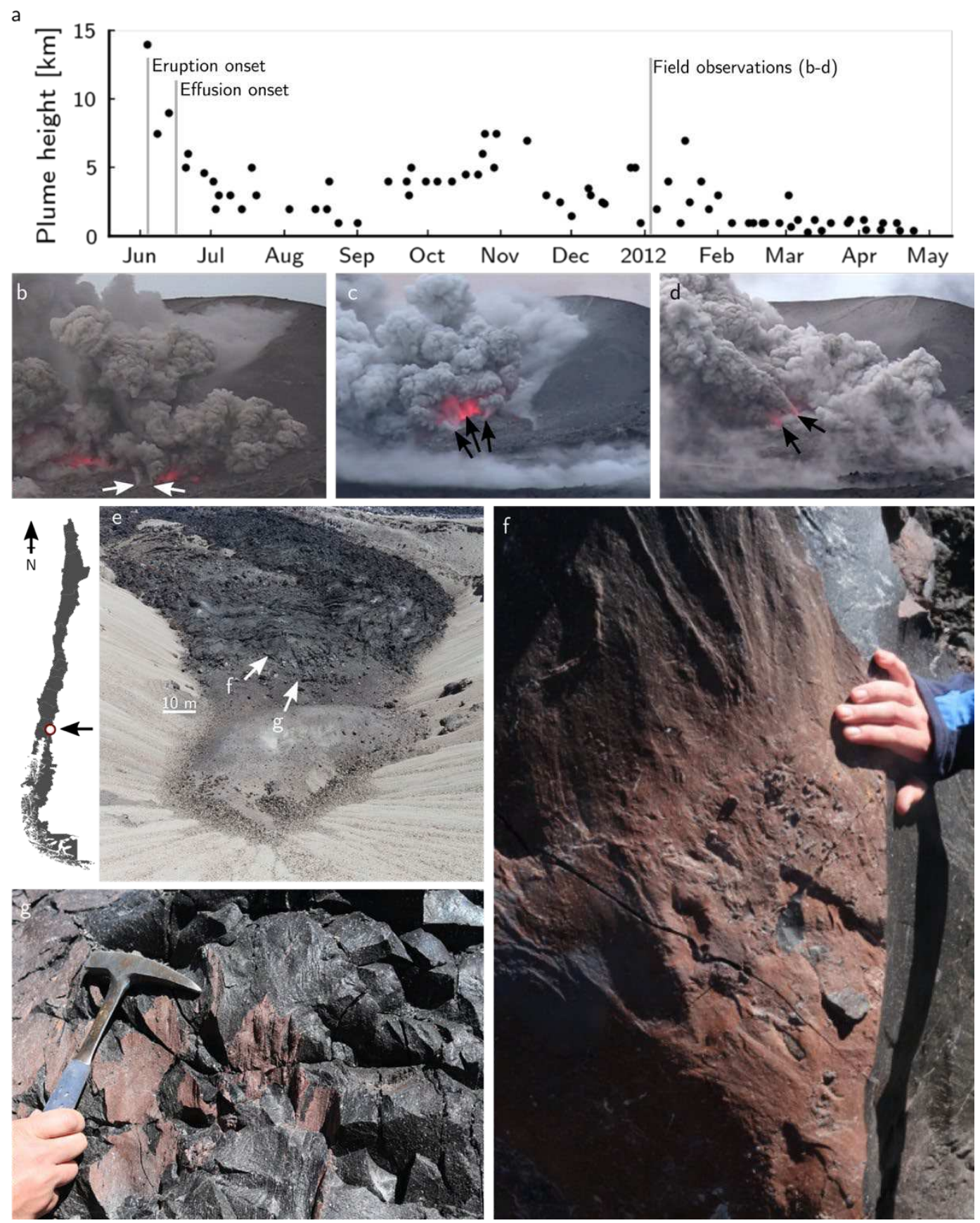

Figure 1 Syn- and post-eruption observations at Cordón Caulle. a Plume height over time, from onset in July 2011 until May 2012 (see ref. 25). Onset of effusion (i.e. hybrid phase) is highlighted, as is the date of on-site observations shown in $\mathbf{b}-\mathbf{d}$. b-d Video frames recorded in January 2012 showing the main Cordón Caulle vent region. Arrows highlight discrete, semi-transient ash vents. e Vent region in 2014. f Detail of reddish veneer coating curviplanar ash-vent surface (see $\mathbf{e}$ for location). $\mathbf{g}$ As $\mathbf{f}$, detailing ash veneer on hackly lava surface. Inset shows location of volcano. 

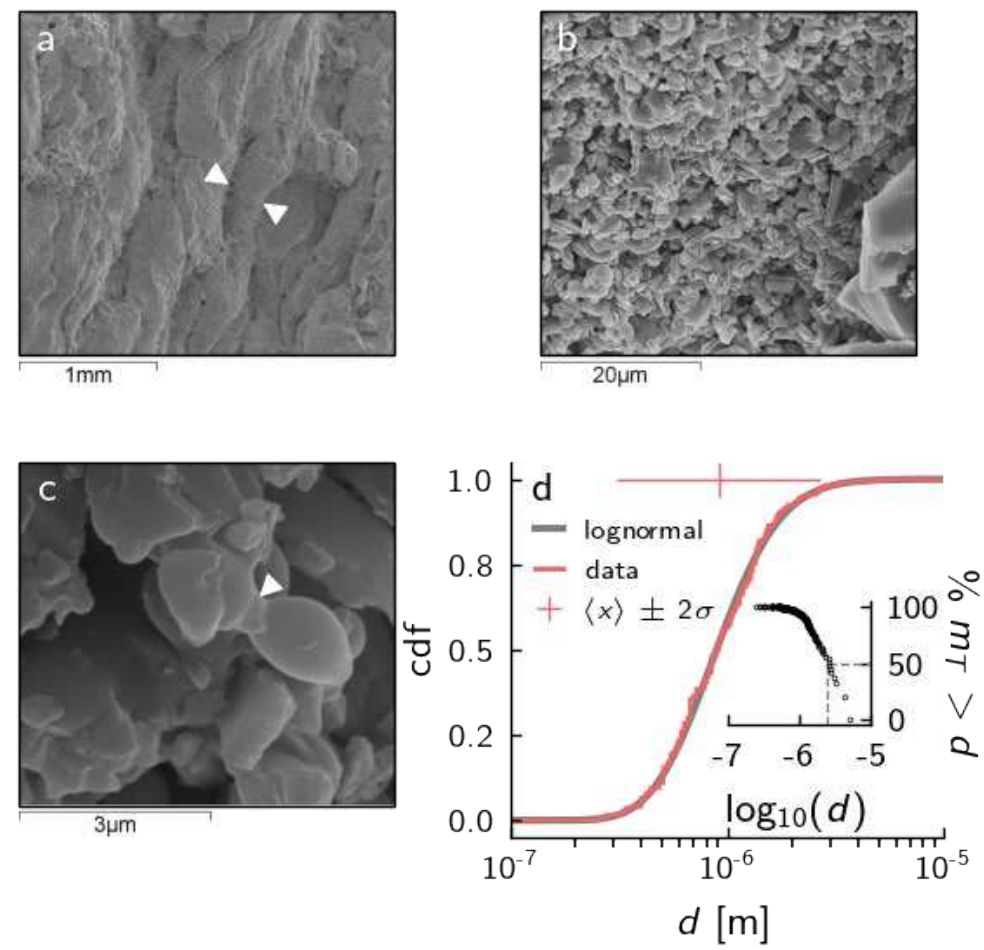

Figure 2 Particle sizes in sintered veneers on in-vent lava fractures that fed ash-venting during hybrid explosive-effusive eruptions. a-c SEM images of fracture-wall surface textures. Ropy textures are highlighted in $\mathbf{a}$; evidence of neck formation highlighted in c. Grainsizes were determined by measuring the major axes of 200 grains in b, yielding a lognormal grainsize distribution (d). d Cumulative distribution (cdf) of particle diameters $d$ (red), compared with a lognormal function $[1+$ $\operatorname{erf}(\ln x-\langle x\rangle / \sigma \sqrt{2})] / 2$ defined by the mean $\langle x\rangle$ and standard deviation $\sigma$ of the logarithm of the data $x$. Marginal histogram shows the density distribution of particles, including $\langle x\rangle$ and $2 \sigma$ range. Inset shows the mass proportion (assuming spherical particles and homogeneous melt density) of particles greater than a given diameter. 


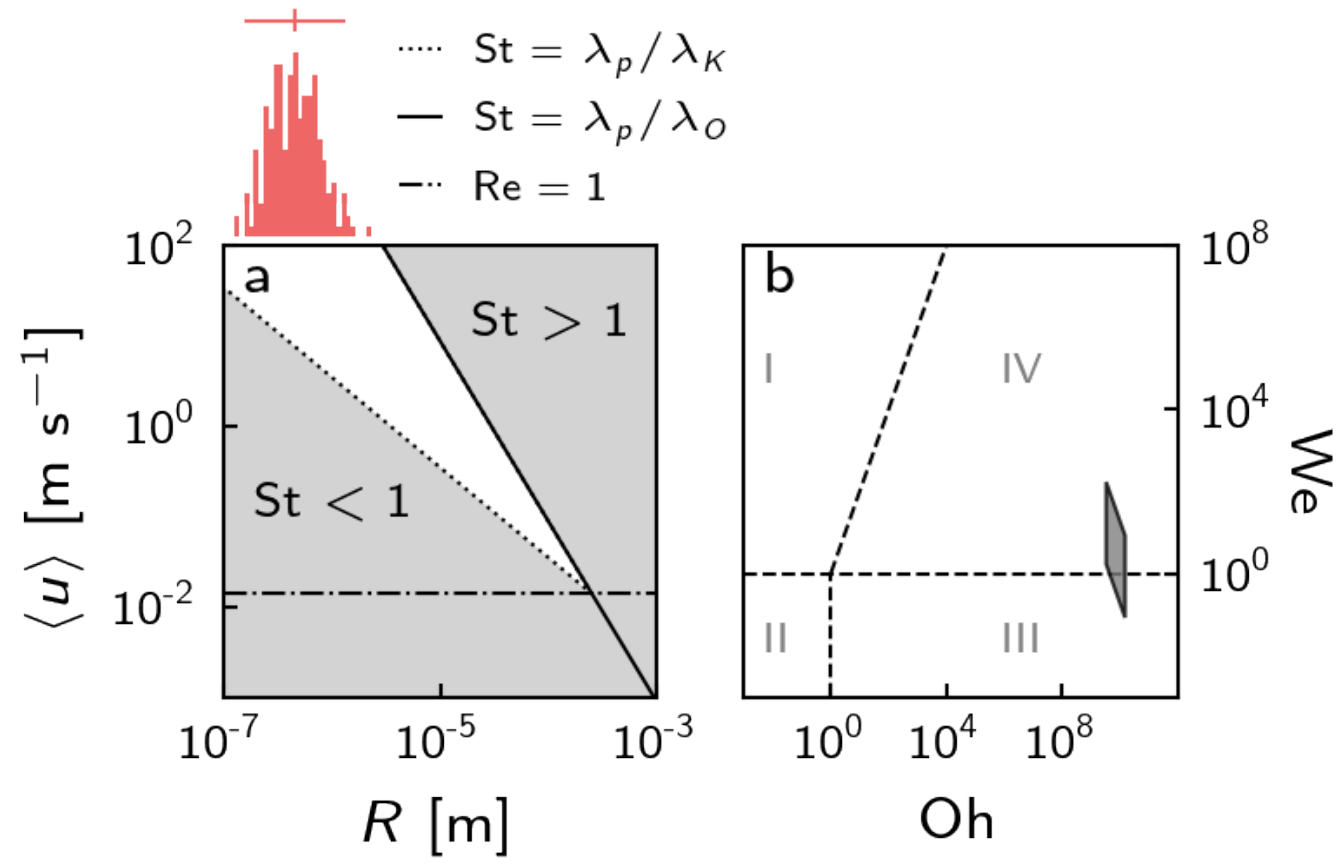

Figure 3 Droplet dynamic regimes. a Stokes number regimes for a $0.01 \mathrm{~m}$ wallbounded flow as a function of velocity and particle radius. The different regimes are delineated according to the maximum and minimum eddy sizes in the flow $\left(\lambda_{O}\right.$ and $\lambda_{K}$, respectively). The particle size distribution of the captured particles is shown in the marginal histogram, with mean and $2 \sigma$ range. $\mathbf{b}$ Weber-Ohnesorge plane for the range of particle sizes, droplet density, surface tension, viscosity, and velocity (see text). The four regimes are: I (inertial impact-driven); II (inertial capillary-driven); III (viscous capillary-driven); IV (viscous impact-driven) ${ }^{40}$. At $\langle u\rangle \sim 100 \mathrm{~m} \mathrm{~s}^{-1}$, We $\gg 1$; at $\langle u\rangle \sim 10 \mathrm{~m}$ $\mathrm{s}^{-1}, \mathrm{We} \sim 1$. 

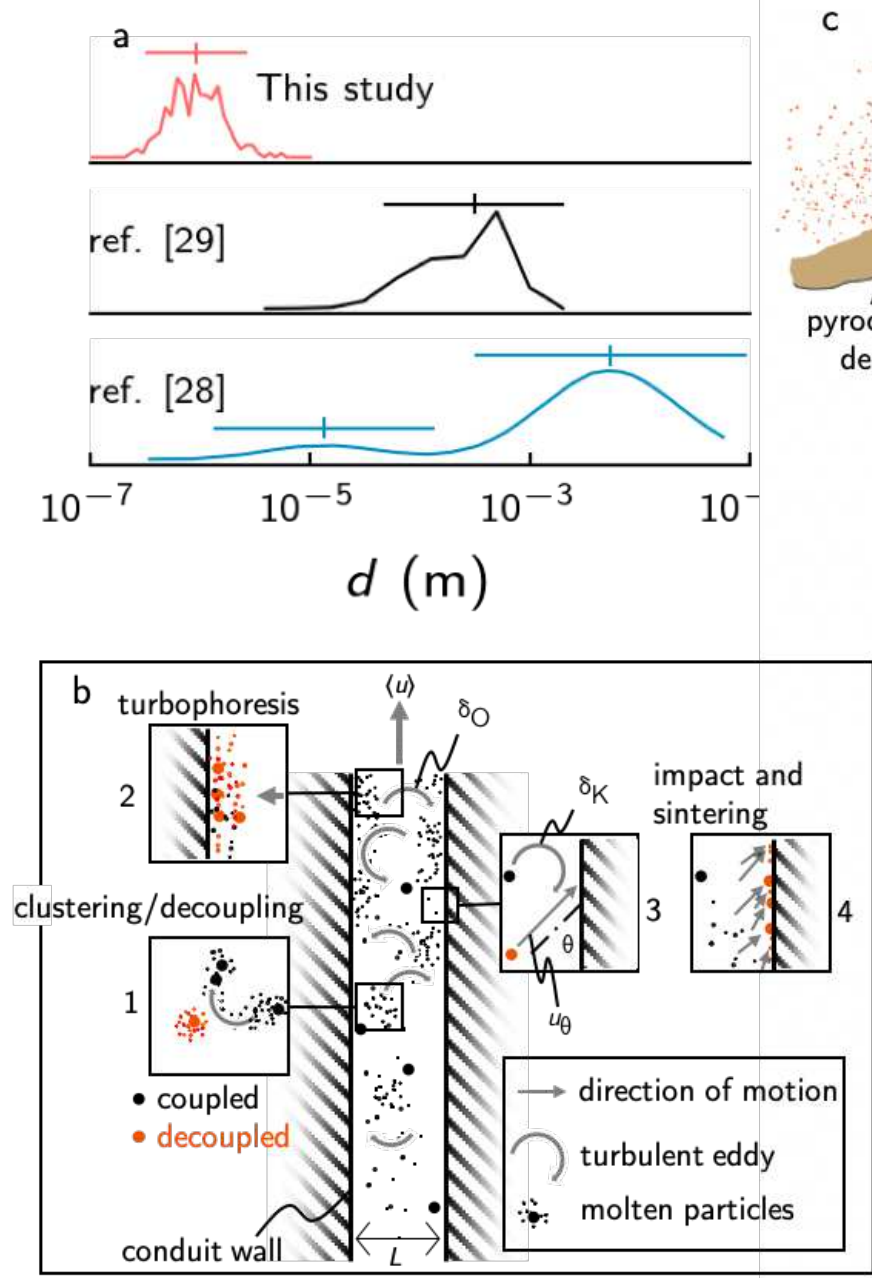

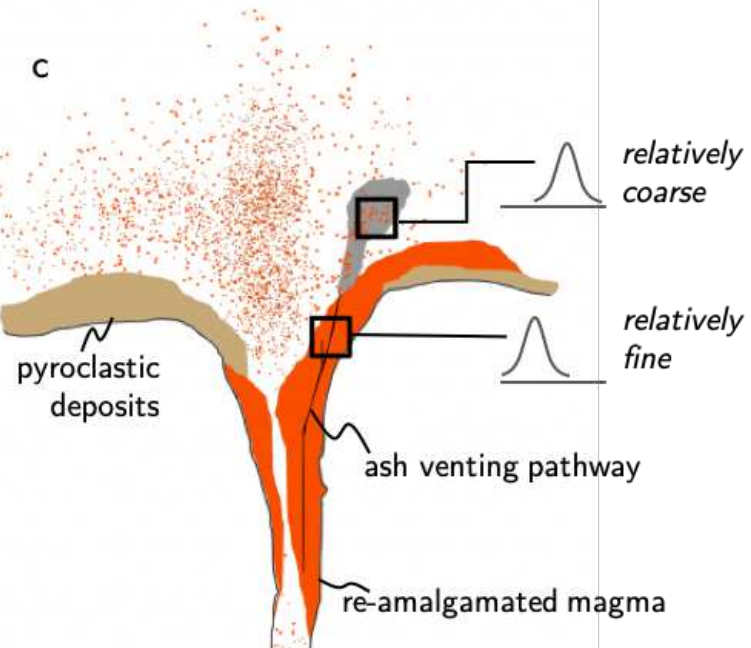

conduit

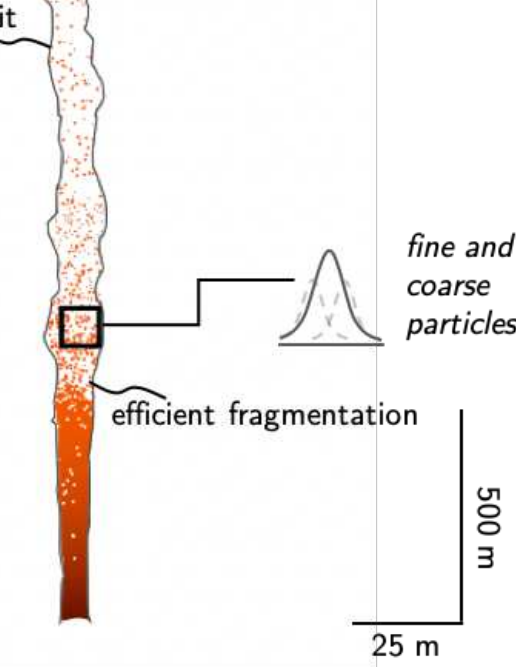

Figure 4 A grain size fractionation model for Cordón Caulle volcano. a Data i $\mathrm{n}$ this study reflect a captured in-conduit fine ash fraction, characterised by a mean diam eter $d$ of $9.12 \times 10^{-7} \mathrm{~m}$. Distribution assumed by Reckziegel et al. [ref. 29] are approxim ately unimodal and described by mean of $d=3.10 \times 10^{-4} \mathrm{~m}$. Data of Costa et al. [ref. 28] , reconstructed from field data, are bimodal, described by lognormal peaks at $d=1.34$ $\times 10^{-5}$ and $d=5.39 \times 10^{-3} \mathrm{~m}$. Mean and $\pm 2 \sigma$ range are highlighted for data of this stud $y$ and ref. 29; these values are shown for each of the peaks of ref. 28. $\mathbf{b}$ In-conduit proces ses summarised schematically. Magmatic particles are transported in a gas phase at a me an velocity of $\langle u\rangle$. Flow turbulence results in clustering and decoupling of particles (1) of St $\geq 1$ from the eddy motion, in addition to turbophoresis (2) which results in elevated c oncentration of particles at the wall. Particles may then impact the wall (3) at velocity $u_{\theta}-$ dependent on $\theta$-then sinter rapidly (4). c Energetic fragmentation within the conduit ge nerates a population of both fine and coarse particles; due to the processes outlined in $\mathbf{b}$, the relatively fine fraction is preferentially captured at the walls of ash vents; the emitted ash therefore predominantly reflects the coarser fraction of the original population. Dia gram inspired by ref. 2. 

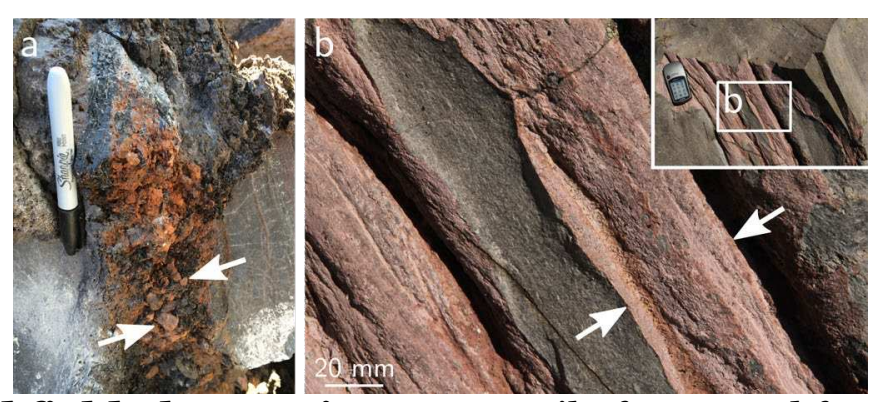

Figure 5 Extended field observations. a Detail of veneered fracture surface distal $\mathrm{fr}$ om the main vent at Cordón Caulle. Arrows highlight millimetric-to-centimetric clasts si ntered to the fracture surface. Sharpie Marker pen is $\sim 14 \mathrm{~cm}$; photograph by J. Castro. b Detail of a veneered fracture surface at Little Glass Mountain (Medicine Lake volcano, $n$ orthern California). Reddish ash-coated surface is highlighted by the arrows. Inset show $\mathrm{s}$ ash-coated surface in context of exposed fracture plane. Photographs by H. Tuffen. 


\section{Data availability}

All data necessary for analysis and reproduction of figures is provided at the following archived repository: https://github.com/jifarquharson/cordon-caulle-ash-vents.

\section{Code availability}

Python code used to analyse and plot data are provided in a Jupyter Notebook at the following archived repository: https://github.com/jifarquharson/cordon-caulle-ashvents.

\section{Acknowledgements}

HT and JF were supported by a Royal Society University Research Fellowship and fieldwork by FW was financially supported by the EC-FP7 Vuelco project. HT, JC, and CIS thank Alex Barria and Miguel Obando for logistical assistance in the field. Carmel Pinnington assisted with SEM imaging. We thank Lionel Wilson and Duncan Woodcock for discussion of particle transfer through pathways. 